\title{
Can partial project selection improve conservation auction performances?
}

\begin{abstract}
Conservation auctions often follow an 'all or nothing' bid selection approach, which restricts selection of the most suitable parts of a submitted project. The problem with 'lumpy' (or all-or-nothing) project selection has been identified in the literature as a major problem in conservation policy; however, the extent of the problem has been rarely quantified. Using an actual conservation tender dataset from Tasmania, the effect of the approach was estimated. This study finds that with a relatively small budget, the cost-effectiveness loss could be as high as one-quarter. To avoid such problem, a partial bid selection could be applied, which could improve the targeting of environmental programs while being administratively less complicated for environmental planners to implement compared to a combinatorial bidding. The basic principle of a partial bid selection is to invite a single project from each landholder with the option for the environmental planning agency to partially select sections of the offer lands that maximise achievement of the agency's policy objectives. In the case of a partial selection, the landholders are paid a bonus (in inverse proportion of actual selection) to compensate for their potential loss of economies of scale and economies of scope. A sensitivity analysis with different bid and ecological value correction factors shows that when the corrections are low, the partial selection approach could be more cost-effective than an 'all or nothing' approach. The results indicate that agencies should consider alternative project selection approaches with better targeting capabilities.
\end{abstract}

Key word: Conservation payment, Cost-effectiveness, Lumpy bid selection, Private land conservation, Project selection 


\section{Introduction}

The expansion and intensification of changed land management practices over the past decades has led to significant habitat destruction and associated loss of biodiversity and ecosystem services (Schroeder et al. 2013). To encourage land use practices that better support biodiversity conservation, governments are providing incentive payment schemes (Bamière et al. 2013, Ruto \& Garrod 2009). Armsworth et al. (2012) highlights the key nature of these schemes as payments to farmers for a fixed duration in return for management actions or the use of more environmentally friendly farming practices.

The US Department of Agriculture (USDA) pioneered the use of auction based mechanisms to select suitable environmental projects under its Conservation Reserve Program (CRP). Auctions are useful for conservation payment as they can, under appropriate conditions ${ }^{1}$, result in efficient and cost effective outcomes (Latacz-Lohmann \& Hamsvoort 1997; 1998). As a result, auction-based conservation incentive payments are gradually gaining popularity in Australia, the United States, Canada and Europe (Boxall et al. 2013) ${ }^{2}$. For example, the Australian State and Federal governments recently implemented 'BushTender", 'EcoTender' and 'Auction for Landscape Recovery', as well as a series of pilot programs under a national market based instruments program.

Within such programs, landholders are likely to focus on the few projects that are best aligned with their farm management plans because transaction costs of preparing bids can be substantial (Mettepenningen et al. 2009). As a result, the number of bids submitted by a participating landholder tends to be low. Under the CRP of the USDA, the average number of contracts per participating landholder is 1.79. Respective estimates for particular sign-up types are 1.49 (general), 1.51 (Conservation Reserve Enhancement Program), 1.66 (Non Conservation Reserve Enhancement Program), and 1.29 (Farmable Wetland) (USDA 2012). In Australia, the average number of bids submitted by participating landholders is also low. For example, the average number of bids per participant was 1.31 for the Auction for Landscape Recovery Project (ALR), 2.38 for EcoTender, 1.63 for Fitzroy Basin Association's Biodiversity auction, and 1.16 for the Southern Rivers Bush Incentives (Iftekhar et al. 2012a). The low numbers of offers are often a result of institutional restrictions (landholders often are restricted to single bids, rather than separate bids for different parts of their land). However, agencies usually employ an 'all or nothing' project selection criterion, where winning projects (bids) are selected in their entirety (Iftekhar et al. 2014).

\footnotetext{
${ }^{1}$ Such conditions could include sufficient participation by eligible bidders, use of appropriate auction format and adequate competition among the participating bidders.

${ }^{2}$ Despite the growing use of such instruments and significant environmental outcomes, participation rates tend to be relatively low, commonly $10 \%$ or less. Low participation rates in U.S. Farm Bill conservation programs have been attributed to differences in farm, family and community characteristics (Reimer \& Prokopy 2014).
} 
Such 'all or nothing' bid selection processes have the advantage of being simpler to administer, easier to explain to potential participating landholders, and landholders have full control over the project because they can design their project according to their farm management plan. However, such designs have potential efficiency losses. Submitted bids tend to be 'lumpy' in that they are an averaging of the values across the land offered. Landholders cannot, or often do not, divide their land into multiple offers with differing ask prices reflective of their relative values and opportunity costs (Chan et al. 2003). Moreover, projects could include areas with limited contribution to program outcomes. In the absence of partial project selection, agencies do not have the option to select the most suitable part(s) of the project to maximize expected environmental benefits within the available budget (Connor et al. 2008). Understanding the potential impact of such an inflexible 'all or nothing' project selection approach on the overall cost effectiveness of the conservation programs would be helpful in improving current environmental fund allocation (Hailu \& Thoyer 2007). However, there is a lack of such estimations based on actual bid price information submitted in conservation tenders.

This article explores the impact of 'discreteness' or 'lumpiness' in conservation project selection using bids submitted under the Midlands Biodiversity Hotspot Tender (MBHT), a prominent tender based scheme in Tasmania, Australia (Figure 1). The sensitivity of auction outcomes to an 'all or nothing' project selection approach is considered over a range of budget constraints. The bid data from the original tender are used to explore the feasibility of partial project selection under different bid and ecological benefit adjustment rules. The basic principle is to invite a single project from each landholder with the option for the environmental planning agency to partially select sections of the offer lands that maximise achievement of the agency's policy objectives. In the case of a partial selection, the landholders are paid a bonus (in inverse proportion of actual selection) to compensate for their potential loss of economies of scale and economies of scope. This approach has the potential to improve the targeting of environmental programs while being administratively less complicated for environmental planners to implement compared to a combinatorial conservation auction. In a combinatorial auction, landholders can (and are encouraged to) submit bids on multiple projects with different features, which would allow them maximum freedom to express their preferences. However, combinatorial auctions can be complex and have high transaction costs. One method could be a compromise between running 'all or nothing' project selection approach and a combinatorial auction (Iftekhar et al. 2012b). 


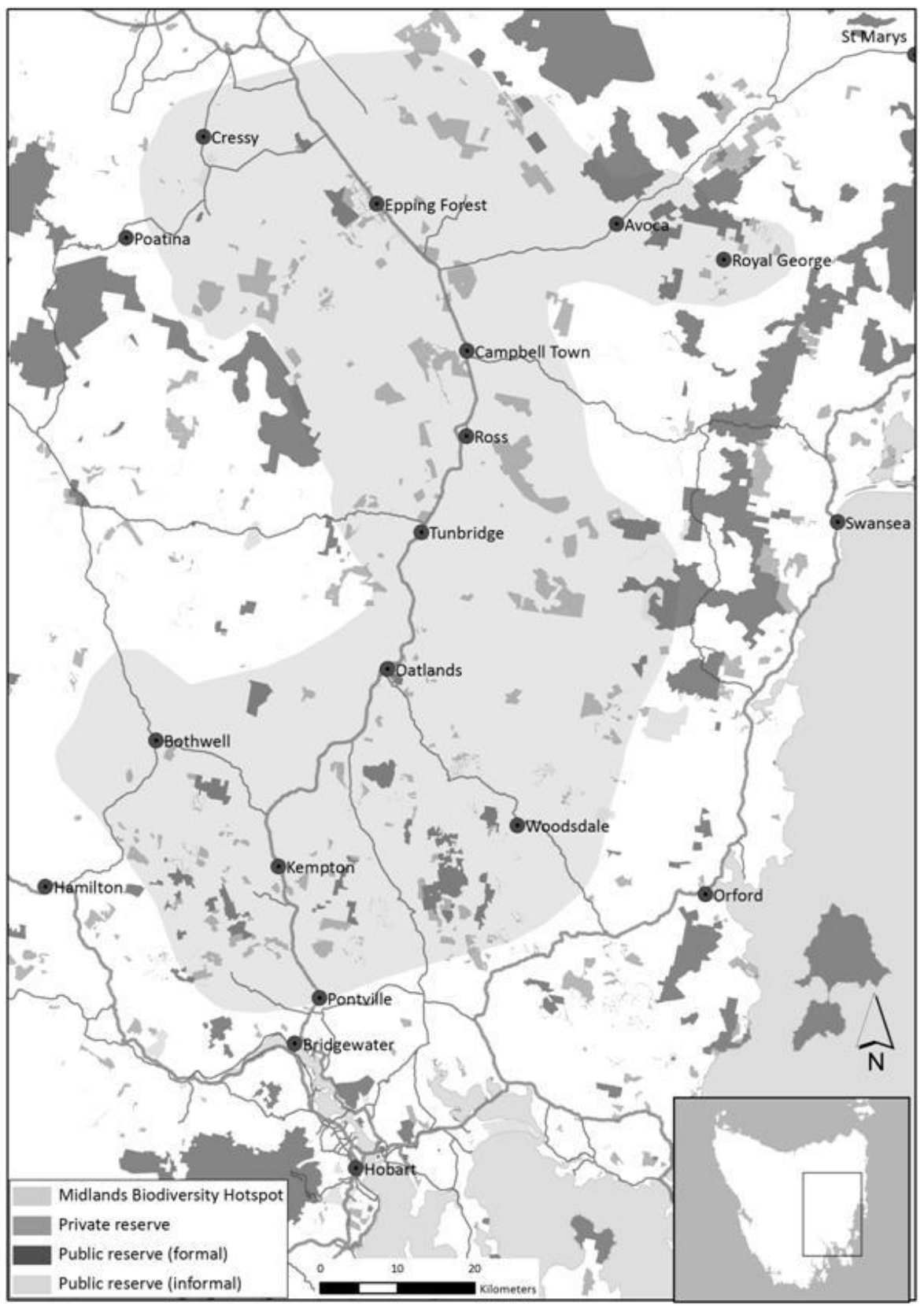

Figure 1: Location of the Midlands Biodiversity Hotspot Tender (MBHT) project

The bidding behaviour of individual landholders is likely to be different in different markets. Nevertheless, determining how the group of people who have submitted bids under MBHT would respond to new regulations (i.e., partial project selection) is difficult without actually running similar auctions with the same group of landholders with new set of rules. Thus, following Stoneham et al. (2003), the analysis that follows is based on the assumption that landholders' bidding would remain the same under all scenarios. Despite such restrictive assumptions, the 'what-if' scenario analysis provides valuable insights on the impact of 'all or nothing' project selection and the feasibility of a partial project selection under different ecological value and bid correction factors, which are described below. 


\section{The model}

The traditional selection process evaluates each offer based on an environmental benefit score, such as a biodiversity benefits index (BBI) or agri-environment index (AEI). These scores are an aggregated weighted sum of individual environmental indices of the attributes of each land parcel offered. Land selection is based on maximising the aggregate environmental benefit subject to a budget constraint (see Hajkowicz et al. (2009) for a review of AEIs).

The agri-environment index used in the MBHT program is similar to the indices developed for funding the Bush Tender program in Australia (Iftekhar et al. 2013). The program objective of MBHT was to maximise the aggregate biodiversity benefits for least cost. Bids were assessed and given an AEI in the form of a conservation value index $(C V I)$. The conservation value index was made up of three elements: (1) biological values (reflecting the presence of vegetation community, threatened species, old growth and landscape connectivity to existing native vegetation); (2) vegetation health condition (based on expert judgment); and (3) conservation value enhancing management actions (such as control of grazing, firewood collection, weeding and feral animal control) (Equation 1)

$$
\begin{array}{cl}
C V I_{i}=C S M_{i} \times T W S_{i} \times \sum_{j}\left(V C S_{i j}+T S S_{i j}+O G S_{i j}+L C S_{i j}\right) \times V H C_{i j} \times a_{i j} \quad \text { Equation 1 } \\
C V I_{i} & \text { Conservation Value Index score of project } i \\
C S M_{i} & \text { Conservation Service Modifier for project } i \\
T W S_{i} & \text { Temporal Weighting Score for project } i \\
V C S_{i j} & \text { Vegetation community score for polygon } j \text { of project } i \\
T S S_{i j} & \text { Threatened species score for polygon } j \text { of project } i \\
O G S_{i j} & \text { Old growth score for polygon } j \text { of project } i \\
L C S_{i j} & \text { Landscape connectivity score for polygon } j \text { of project } i \\
V H C_{i j} & \text { Vegetation Health Condition for polygon } j \text { of project } i \\
a_{i j} & \text { Area of polygon } j \text { of project } i
\end{array}
$$

The CVI was calculated in a stepwise fashion. The biological value scores of each mapped polygon were summed and multiplied by the health score and the polygon's area to get a score for individual polygons. The raw polygon scores were then summed and multiplied by the conservation service modifier score (reflecting management action) and a temporal weighing score (reflecting the duration of the contract) to get a total CVI score for a project. To generate CVI scores for individual polygons, raw polygon scores were multiplied by the conservation management action score and the temporal weighing score. 
Under MBHT, individual landholders submitted whole projects with associated bid prices. Bids were assessed and ranked by their total cost-benefit index (price/CVI). During bid preparation, landholders were informed about the environmental objectives of the program and the environmental matrices used to evaluate their projects. As such, landholders knew the environmental scores of their individual projects. During the site assessment, each single project was mapped as distinct vegetation patches (or polygons), which comprised discrete areas of vegetation that were consistent in terms of their ecological value. This allowed the opportunity to test the potential of a partial (or polygon) selection process. Polygon selection in this context refers to the design where an auctioneer could select a sub-set of polygons (hereafter polygon selection) from a landholder instead of selecting a project in its entirety (hereafter block selection). Comparing the performances of block selection with a polygon selection provides some insight to the influence of discreteness or lumpiness of projects on auction performances.

Under block selection (applied to Equation 2), each bidder submits an offer to fund a project. The bid consists of the price and attributes of the proposed conservation activity. After receiving the bids, the agency prepares a CVI score using the matrix described in Equation 1. Offers are selected based on maximising the environmental benefits, subject to the condition that the total procurement cost does not exceed the environmental planning agency's budget. Assume there are $N\{1,2, \ldots, N\}$ projects submitted in an auction. Each bid or project conveys the information on the bid price $P_{i}$ and the conservation value index score $\left(C V I_{i}\right)$ for that project. The auctioneer's winner determination problem is:

$$
\begin{aligned}
& Z=\max \sum_{i=1}^{N} C V I_{i} x_{i} \\
& \text { s.t. } \sum_{i} P_{i} x_{i} \leq M \quad \text { Equation } 2 \\
& x_{i} \in\{0,1\}
\end{aligned}
$$

Where: $Z$ is the maximized $C V I$ score, subject to the condition that the total procurement cost does not exceed agency's budget $(M)$ and $x_{i}$ is a binary variable indicating whether project $i$ has been selected $\left(x_{i}=1\right)$ or not $\left(x_{i}=0\right)$.

Under the proposed polygon selection approach, submitted projects are disaggregated into subprojects based on individual polygons. That is, a single project or bid was separated into a set of subbids or sub-projects, covering a single distinct vegetation patch or polygon. There are several ways bid prices could be split and assigned to sub-projects (e.g., based on ecological contribution, opportunity costs, or area). In the example dataset, bid price was split among individual polygons in terms of their proportionate area contributions (i.e., $P_{i j}=P_{i} \times a_{i j} / A_{i}$ and $P_{i}=\sum_{j} P_{i j}$ ). Here, $a_{i j}$ and $A_{i}$ are areas of an individual polygon $j$ of project $i$ and total project $i$ respectively. The area of a polygon is considered as an indicator of opportunity costs of a landholder. On the other hand, in the example dataset, CVI 
scores are available for individual polygons. Aggregated $C V I$ scores for individual polygons $C V I_{i j}$ are equal to the total score for the project $C V I_{i}$ (e.g., $C V I_{i}=\sum_{j} C V I_{i j}$ ). As a consequence, if all polygons under a project are selected, the total $C V I$ and bid will be equal to the corresponding figures for the block project.

With polygon selection, agencies have the flexibility to select some polygons, so two non-linear correction functions were used to compensate landholders for potential loss of economies of scope and scale (applied in sub-bid prices) and to penalize the environmental planning agency due to loss of connectivity benefits (applied on CVI score) from selecting fewer polygons from a given landholder. The polygon selection procedure incorporating the correction functions is presented in Equation 3. 


$$
Z=\max \sum_{i=1}^{N} \widetilde{C V} I_{i}
$$

s.t.

$$
\begin{aligned}
& \tilde{P}_{i}=T C C_{i} \times P_{i} \times \delta_{i}+\sum_{j} P_{i j} \times\left(1-T C C_{i}\right) \times\left(1+O C C_{i} \times \frac{A_{i}-\bar{a}_{i}}{A_{i}-\hat{a}_{i}}\right) \times x_{i j} \\
& \widetilde{C V} I_{i}=\sum_{j} C V I_{i j} \times\left(1-C V I C_{i} \times \frac{C S_{i}-\overline{C S}_{i}}{C S_{i}}\right) \times x_{i j} \\
& \overline{C S}_{i}=0.5 \times \sum_{j, k} C S_{j, k}^{i} \times x_{i j} \times x_{i k} \\
& \bar{a}_{i}=\sum_{j} a_{i j} \times x_{i j} \\
& \delta_{i}=1 \text { if } \bar{a}_{i}>0 \\
& \delta_{i}=0 \text { if } \bar{a}_{i}=0 \\
& \sum_{i} \tilde{P}_{i} \leq M \\
& x_{i j} \in\{0,1\}
\end{aligned}
$$

\footnotetext{
$\tilde{P}_{i} \quad$ Revised bid for project $i$

TCC $_{i} \quad$ Transaction Cost Correction factor for project $i$

$P_{i} \quad$ Original block bid for project $i$

$\delta_{i} \quad$ Binary indicator variable reflecting whether any polygon from project $i$ has been selected $\left(\delta_{i}=1\right)$ or not $\left(\delta_{i}=0\right)$

$P_{i j} \quad$ Estimated sub-bid for polygon $j$ of project $i$

$O C C_{i} \quad$ Opportunity Cost Correction factor for project $i$

$\bar{a}_{i} \quad$ Aggregate areas of selected polygons from project $i$

$\hat{a}_{i} \quad$ Area of the polygon with the smallest area of project $i$

$\widetilde{C V} I_{i} \quad$ Revised total $C V I$ score for project $i$

$C V I_{i j} \quad$ Original $C V I$ score for polygon $j$ of project $i$

CVIC $i \quad$ CVI correction factor for project $i$

$C S_{i} \quad$ Total Connectivity Score for project $i$

$\overline{C s}_{i} \quad$ Aggregate connectivity score of selected polygons from project $i$

$x_{i j} \quad$ Binary indicator variable reflecting whether polygon $j$ of project $i$ has been selected $\left(x_{i j}=1\right)$ or not $\left(x_{i j}=0\right)$
} 
Similar to the block selection model (Equation 2), the objective of the polygon selection model is to maximize the total $C V I$ score $(Z)$ within a given budget $(M)$ where selections are being made on individual polygons.

The first constraint in Equation 3 presents the non-linear correction function to compensate landholders for potential loss of economies of scope and scale. It captures the net changes in opportunity and transaction costs as the polygon area gets smaller. It was assumed that the submitted block bid could be divided into two parts: transaction cost and opportunity cost. The transaction cost $\left(T C C_{i} \times P_{i} \times \delta_{i}\right)$ part of the constraint reflects the costs landholders will incur and are relatively fixed no matter how many polygons are selected (Nilsson 2009). Mettepenningen et al. (2009) estimated that individual landholders spent 14.3 per cent of the total cost (per year per hectare) as transaction cost for projects submitted under the European Agri-Environmental Schemes. Similarly, Falconer (2000) observed that private transactions costs could range from five to 10 per cent of the compensation payments received by landholders in Europe. Following these observations, it was assumed that a fixed proportion $\left(T C C_{i}\right)$ of the original block bid $\left(P_{i}\right)$ could be considered a transaction $\operatorname{cost}^{3}$. The landholder receives this fixed amount if any polygon is selected from the landholder (i.e., $\delta_{i}=1$ ).

The second part of the first constraint reflects the correction to the variable opportunity costs for the selected polygons. It was assumed that the landholder receives the highest rate of opportunity cost correction $\left(O C C_{i}\right)$ from a project if only the polygon with the smallest area $\left(\hat{a}_{i}\right)$ is selected, i.e., the corresponding value of the sub-bid is increased by the maximum amount. This has been done to reflect the fact that selecting only one or two polygons from a landholder's offer may be very inconvenient (i.e. a small patch in the middle of a larger paddock) and hence have very high relative opportunity costs (Ducos et al. 2009). However, as more polygons from a single project (or landholder) are selected, the rate of compensation declines. The rate of decline is a function of the ratio between the aggregate area of the selected polygons and the total area of the project. The highest amount of compensation (both $T C C_{i}$ and $O C C_{i}$ ) could vary from landholder to landholder depending on their farm layouts and enterprise type.

The second constraint in Equation 3 presents the penalty function imposed on the environmental planning agency due to loss of connectivity benefits from selecting some sub-projects from a landholder. Such correction is necessary in the example dataset, as the standard CVI measures (Equation 1) for individual polygons did not capture the inter-connectivity between polygons within a project. Therefore, the connectivity correction captures the loss of inter-connectivity from selecting few polygons. Selecting only a single polygon from a project will allow polygons with higher CVI to be selected, but the scores will be offset by reduced connectivity.

\footnotetext{
${ }^{3}$ It is possible to assume other specifications, such as fixed uniform amount for every landholder or variable amounts depending on project areas or other attributes.
} 
Following this premise, the maximum $C V I$ correction penalty $\left(C V I C_{i}\right)$ is imposed if only a single polygon is selected from a given project (i.e., the corresponding CVI score of the polygon is reduced by the maximum rate). On the other hand, as the number of connected sites / polygons selected increases, the $C V I$ values of the selected polygons also increase. The rate of increase is again a function of the aggregate connectivity score of the selected polygons and the total connectivity score of the project. For a given project, a connectivity score is prepared by calculating the number of polygons sharing borders with each other. For example, if two polygons $\{j, k\}$ of a project share borders, then $c s_{j, k}^{i}=1$, otherwise $c s_{j, k}^{i}=0$. The total number of polygons sharing borders in a project is then $\overline{c s_{i}}=0.5 \times \sum_{j, k} c s_{j, k}^{i}$. The aggregate connectivity score of the selected polygons $\left(\overline{C S}_{i}\right)$ is calculated in a similar fashion, but in this case both polygons $\{j, k\}$ need to be selected.

In essence, corrections in bid prices and CVI scores ensure that if projects are partially selected, then the total amount paid is higher than the amount that would have been paid under a linear reduction, and the aggregate CVI score is lower than total score with linear reduction. However, if the project is selected in its entirety, the landholder receives the original bid price and CVI score. To demonstrate these correction functions, the corrected $C V I$ and bid prices were plotted for an example project with total area of 100 ha, total CVI score of 1000 and bid price of $\$ 500$. Further, it was assumed that the project is composed of twenty equal sized polygons (with equal $C V I$ scores and bids prices) and every polygon share borders with each other (i.e. $\overline{C s}_{i}=10$ ). The values of $T C C_{i}, O C C_{i}$ and $C V I C_{i}$ are set to $0.20,0.50$ and 0.50 respectively. Therefore, if only a single polygon is selected then the CVI score would be reduced by half. The polygon will receive a transaction cost of $\$ 100$ (which is $20 \%$ of the total bid) and an adjusted opportunity cost of $\$ 30\left(\$ 25 \times(1-0.20) \times\left(1+0.5 \times \frac{100-5}{100-5}\right)\right.$. However, these values would be close to the original estimates as more polygons (and more areas) from the project are selected (Figure 2). When all the polygons are selected the total bid price and the CVI scores are the same as the full project estimates. 

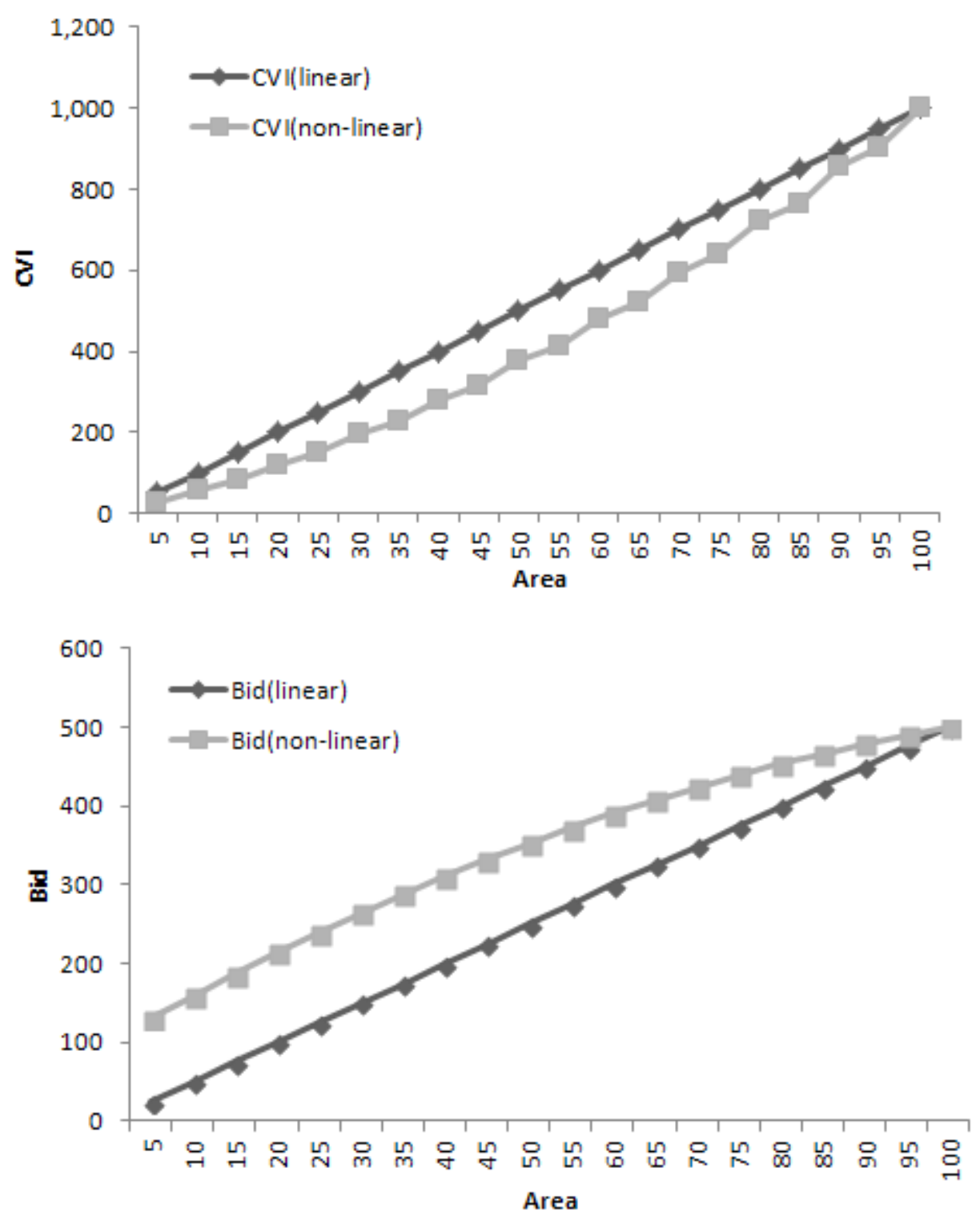

Figure 2: Response of the total CVI score and bid prices for a sample project when different proportion of area is selected under non-linear and linear conversion.

Under non-linear conversion the values of $T C C_{i}, O C C_{i}$ and $C V I C_{i}$ have been set equal to $0.20,0.50$ and 0.50 respectively. Under linear conversion these values are set equal to zero.

In the following sections the performance of the proposed mechanism is tested using a dataset on bids (projects) submitted under theMBHT conducted in Tasmania, Australia. 


\section{Material and Methods}

The simulation analysis used the bids submitted to the MBHT. This was a voluntary biodiversity conservation program for landholders in the Northern Midlands Bioregion of Tasmania (Iftekhar et al. 2013). The purpose of the tender was to maximize conservation outcomes with the funds available, test the cost efficiency of a tender approach, and set market values for the various conservation values and services. The MBHT auction was conducted as a sealed-bid discriminative price auction. Offers were developed with the assistance of field officers who evaluated and then assigned a biodiversity metric to each proposal. Data for the analysis, sourced from the Tasmanian Land Conservancy (TLC) database, included bid prices and relevant CVI scores for 54 projects submitted in 2007 under the MBHT program (Table 1).

Table 1: General bio-physical characteristics of the submitted bids under the MBHT

\begin{tabular}{lrr}
\hline Characteristics & Mean & Co-efficient of Variation \\
\hline Area (Ha) & 185.64 & 1.47 \\
CVI score & $2,030.29$ & 1.54 \\
Bid (\$) & $180,077.81$ & 2.40 \\
CVI/\$ & 0.02 & 1.41 \\
\hline Broad vegetation type & & \\
$\quad$ Dry eucalypt (Ha) & 160.86 & 1.31 \\
$\quad$ Native grassland (Ha) & 47.01 & 1.44 \\
$\quad$ Non eucalypt (Ha) & 30.40 & 2.73 \\
\hline Number of polygons (distinct vegetation patches) & 12.00 & 0.97 \\
\hline
\end{tabular}

Using the original and unchanged tender data, this study explores the performances of a polygon selection mechanism under non-linear project evaluation and pricing functions. Simulation experiments were conducted in three main dimensions: $T C C_{i}, O C C_{i}$ and $C V I C_{i}$.

- The first dimension involved estimating the sensitivity of the auction performances for five levels of transaction cost proportion (starting from 0 with an equal increment of 0.05 ; represented as TCC_0, TCC_0.05, TCC_0.10, TCC_0.15 and TCC_0.20 respectively). This range was selected based on Falconer (2000), who estimated that the proportion of transaction cost could range from 5 to 15 per cent of the total payment received.

- The second dimension involved testing the influence of maximum $O C C_{i}$ value given three homogenous scenarios, with values of $O C C_{i}$ equal to 0 (OCC_0), 0.25 (OCC_0.25) and 0.50 (OCC_0.50) respectively. A mixed scenario (OCC_M) was also considered where the bidders received a lower value $(0.25)$ if the connectivity score of the project was greater than the average 
connectivity score of all submitted bids. The remaining bidders received a higher value (0.50). This scenario was constructed to reflect the assumption that the selection of not connected sub-projects generate higher opportunity costs than sub-projects that are connected; therefore, projects with high connectivity scores should receive smaller corrections in bid prices.

- The third dimension examined the impact of $C V I C_{i}$ values with three homogenous scenarios (starting from 0 with an equal increment of 0.25 ; represented as CVIC_0, CVIC_0.25 and CVIC_0.50 respectively) and a mixed scenario (CVIC_M). In the mixed scenario, the bidders with project areas larger than average areas of all submitted bids received a maximum value of 0.25 . The remaining bidders received a higher value (0.50). This was done to reflect the scenario where connectivity of polygons plays a relatively smaller role in the provision of ecological services when individual polygons are relatively large.

With a budget constrained auction, the amount of environmental services secured depends on the intersection between supply curve and the budget constraint. To test the performance of block and polygon selections for a $T C C_{i}$, OCC $_{i}$ and $C V I C_{i}$ combinations, the optimization models ${ }^{4}$ (Equations 2 and 3) was run twenty times with a gradually relaxing budget constraint and varied the budget from $\$ 0.50$ million to $\$ 10$ million with a $\$ 0.50$ million increment ${ }^{5}$. This allowed analysis of supply responses to budgetary constraints under each combination of $T C C_{i}, O C C_{i}$ and $C V I C_{i}$.

To calculate the influence of budget constraint in the optimization model, the starting point was set at the minimum budget constraint (i.e., $\$ 0.50$ million). For a fixed budget, projects were selected based on their total $C V I$ score subject to budget constraints. The total CVI score and total payment were calculated by summing the CVI scores and the bid prices of successful projects. CVI score per dollar (CVI/\$) was calculated by dividing the total $C V I$ score by total payment. These steps were repeated for each budget constraint using the original and unchanged set of bids.

Block and polygon selections are compared in terms of the average of the selection outcomes (such as CVI, CVI/\$ and vegetation coverage) obtained under different budget constraints. Nonparametric tests (Wilcoxon Signed Ranks Tests) were used to compare the performances of block and polygon selections.

\footnotetext{
${ }^{4}$ Solved using General Algebraic Modelling System (GAMS@)

${ }^{5}$ With a budget of $\$ 9.8$ million, all submitted bids are selected. However, bidders did not have information about the total budget available for the program.
} 


\section{Results}

The results from the sensitivity analysis on the relative performance of block and polygon selection begins with a presentation of the overall conservation value outcomes (conservation value index score), followed by composition of broad vegetation types and cost-effectiveness (CVI/\$).

\section{Conservation Value Index}

Analysing the total $C V I$ score achieved for the scenario with no correction factors (i.e., $T C C_{i}, O C C_{i}$ and $C V I C_{i}$ values are zero) demonstrates the effect of budget constraints on the performances of polygon and block selection. Figure 3 presents the CVI scores for each factor. The polygon selection approach has secured higher total $C V I$ scores compared to block selection for most of the budget range (except for very high budget). Both selection algorithms try to maximize the total CVI scores by including as many projects as possible within a given budget. A high value-high cost project will be selected over a low value-low cost project if it improves the total CVI scores without exceeding the budget. Polygon selection has a larger set of options (individual polygons) to make these choices compared to block selection (operating at project level). As a result, the total CVI score curve is smoother for polygon selection compared to block selection. Due to the unevenness, the absolute difference between these two selection mechanisms is most prominent in the budget range of $\$ 5.5$ million to $\$ 6.5$ million, whereas, the relative differences are highest for low budget scenarios. For example, compared to block selection, polygon selection has achieved 23, 26 and 15 per cent higher $C V I$ scores with $\$ 0.50, \$ 1$ and $\$ 1.5$ million budget constraints respectively. With very high budgets, both programs perform similarly. 


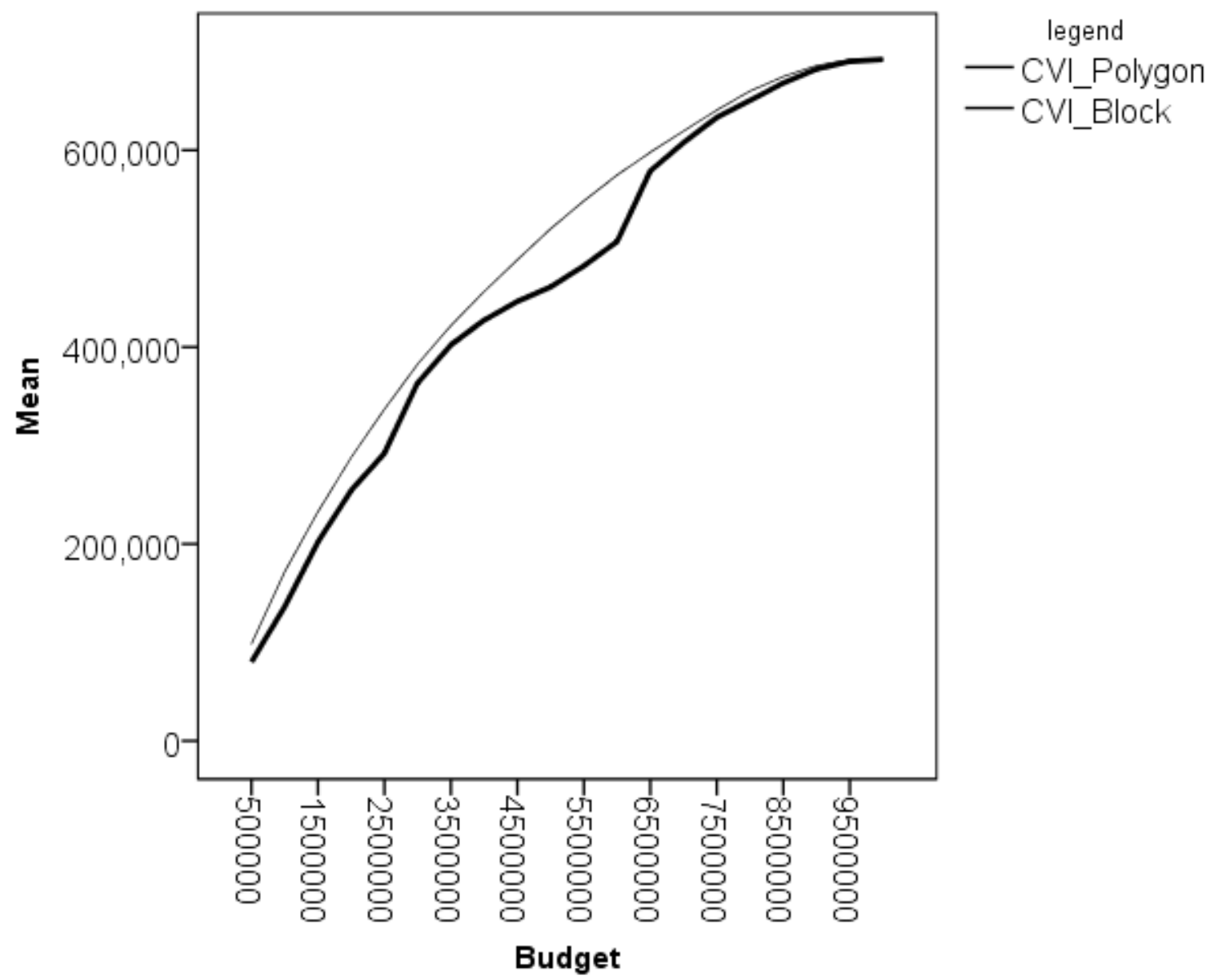

Figure 3: Total conservation value index (CVI) score for block selection and polygon selections for different budget constraint for the scenario with no correction factor (i.e., $T C C_{i}, O C C_{i}$ and $C V I C_{i}$ values set to zero).

When the mean CVI scores (over budget constraint range) against different $T C C_{i}, O C C_{i}$ and $C V I C_{i}$ value combinations are plotted, it can be observed that polygon based selection is able to secure a higher $C V I$ score when $T C C_{i}, O C C_{i}$ and $C V I C_{i}$ values are low (Figure 4). For example, with TCC_0, TCC_0.05 and TCC_0.10 scenarios the average CVI scores for polygon selection are significantly higher for medium (0.25) levels of $O C C_{i}$ and $C V I C_{i}$ and values (Table 2). Polygon selection achieves lower $C V I$ scores than block selection with high $(0.50) O C C_{i}$ and $C V I C_{i}$ value combinations. 
TCC

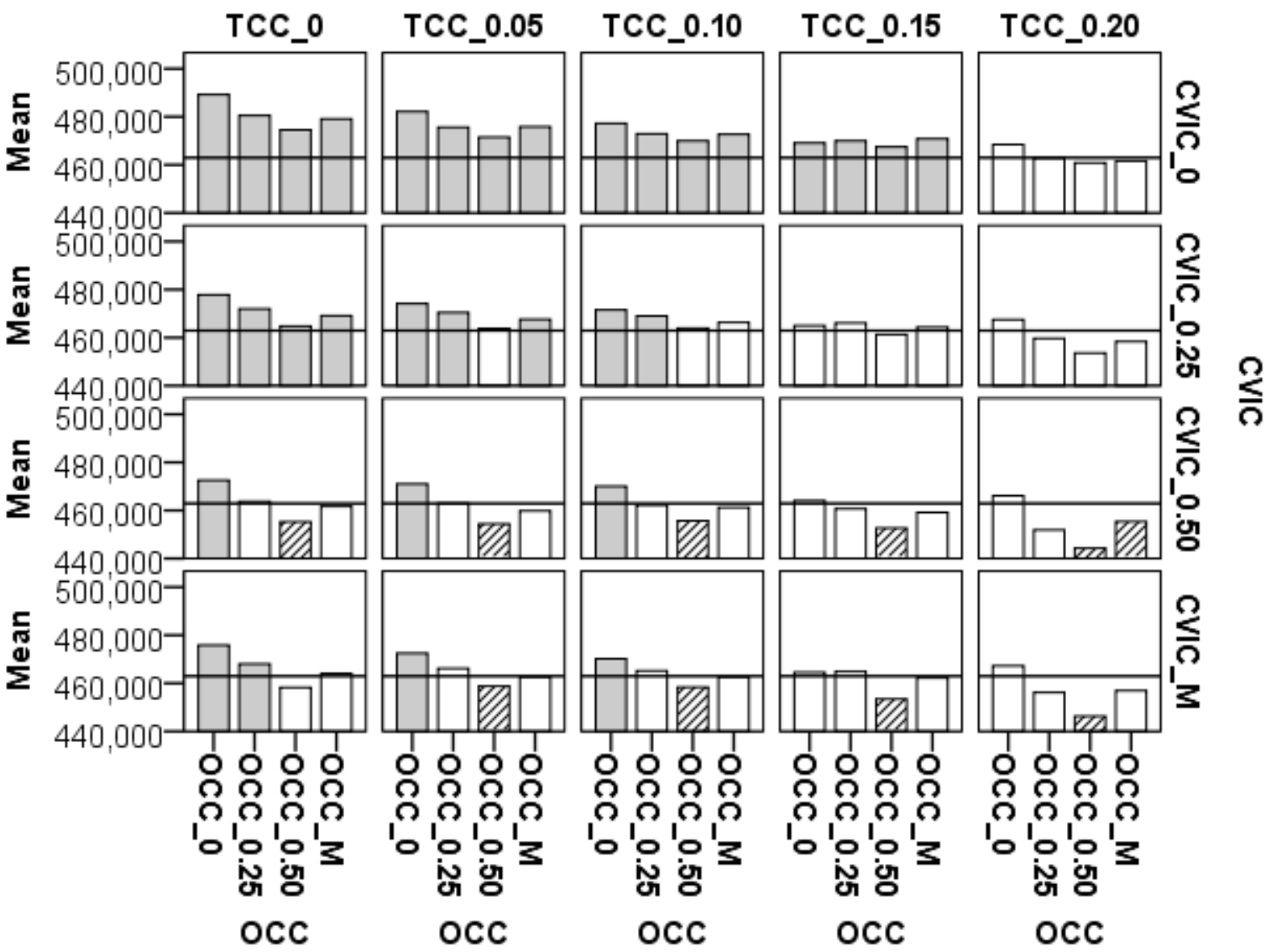

Figure 4: Average conservation value index (CVI) score for block selection and polygon selections with different TCC $_{i}$, OCC $_{i}$ and $C V I C_{i}$ values.

Each point represents average of optimization results for twenty levels of budget constraints. Reference line indicates estimate for block selection. Shaded, checked and blank bars indicate significantly better performance by polygon selection, by block selection and no significant difference respectively at 10 per cent level of significance based on Wilcoxon Signed Ranks Test (Table 2). 
Table 2: Z statistics Wilcoxon Signed Ranks Test: Comparison between block selection and polygon selections with different of $T C C_{i}, O C C_{i}$ and $C V I C_{i}$ values

\begin{tabular}{|c|c|c|c|c|c|c|c|c|c|c|c|c|}
\hline \multirow[t]{3}{*}{ TCC } & \multirow[t]{3}{*}{ CVIC } & \multirow[t]{3}{*}{ OCC } & \multicolumn{2}{|c|}{$\begin{array}{l}\text { Ecological } \\
\text { outcomes }\end{array}$} & \multicolumn{6}{|c|}{ Broad vegetation } & \multicolumn{2}{|c|}{$\begin{array}{c}\text { Cost- } \\
\text { effectiveness }\end{array}$} \\
\hline & & & \multicolumn{2}{|c|}{ CVI } & \multicolumn{2}{|c|}{ Dry eucalypt } & \multicolumn{2}{|c|}{ Native grass } & \multicolumn{2}{|c|}{$\begin{array}{l}\text { Non } \\
\text { eucalypt }\end{array}$} & \multicolumn{2}{|c|}{$C V I / \$$} \\
\hline & & & $\mathrm{Z}$ & $\mathrm{P}$ & $\mathrm{Z}$ & $\mathrm{P}$ & $\mathrm{Z}$ & $\mathrm{P}$ & $\mathrm{Z}$ & $\mathrm{P}$ & $\mathrm{Z}$ & $\mathrm{P}$ \\
\hline \multirow[t]{16}{*}{ TCC_0 } & \multirow[t]{4}{*}{ CVIC_0 } & OCC_O & -3.82 & $* *$ & -0.81 & & -3.46 & $* *$ & -3.42 & $* *$ & -3.92 & $* *$ \\
\hline & & OCC_0.25 & -3.82 & $* *$ & -0.89 & & -3.14 & $* *$ & -2.90 & $* *$ & -3.92 & $* *$ \\
\hline & & OCC_0.50 & -3.78 & $* *$ & -0.08 & & -2.70 & $* *$ & -2.09 & $*$ & -3.88 & $* *$ \\
\hline & & OCC_M & -3.82 & $* *$ & -0.97 & & -3.46 & $* *$ & -2.64 & $* *$ & -3.92 & $* *$ \\
\hline & \multirow[t]{4}{*}{ CVIC_0.25 } & $\mathrm{OCC}_{-} 0$ & -3.82 & $* *$ & -0.08 & & -3.54 & $* *$ & -0.16 & & -3.92 & $* *$ \\
\hline & & OCC_0.25 & -3.70 & $* *$ & -0.89 & & -3.74 & $* *$ & -0.64 & & -3.73 & $* *$ \\
\hline & & OCC_0.50 & -1.73 & $\wedge$ & -1.73 & $\wedge$ & -3.50 & $* *$ & -1.37 & & -1.90 & $\wedge$ \\
\hline & & OCC_M & -2.74 & $* *$ & -0.44 & & -3.74 & $* *$ & -0.15 & & -2.95 & $* *$ \\
\hline & \multirow[t]{4}{*}{ CVIC_0.50 } & OCC_0 & -3.82 & $* *$ & -0.68 & & -3.34 & $* *$ & -1.57 & & -3.92 & $* *$ \\
\hline & & OCC_0.25 & -0.28 & & -2.29 & $*$ & -3.42 & $* *$ & -1.69 & $\wedge$ & -0.34 & \\
\hline & & OCC_0.50 & -2.82 & $* *$ & -3.18 & $* *$ & -3.74 & $* *$ & -1.49 & & -2.76 & $* *$ \\
\hline & & OCC_M & -1.01 & & -3.26 & $* *$ & -3.82 & $* *$ & -1.49 & & -1.16 & \\
\hline & \multirow[t]{4}{*}{ CVIC_M } & OCC_0 & -3.70 & $* *$ & 0.00 & & -3.62 & $* *$ & -0.16 & & -3.81 & $* *$ \\
\hline & & OCC_0.25 & -2.37 & $*$ & -0.77 & & -3.82 & $* *$ & -0.93 & & -2.35 & $*$ \\
\hline & & OCC_0.50 & -1.33 & & -2.33 & $*$ & -3.62 & $* *$ & -0.97 & & -1.12 & \\
\hline & & OCC_M & -0.08 & & -0.60 & & -3.82 & $* *$ & -0.50 & & -0.30 & \\
\hline \multirow[t]{16}{*}{ TCC_0.05 } & CVIC_0 & $\mathrm{OCC}_{-} 0$ & -3.78 & $* *$ & -1.17 & & -3.26 & $* *$ & -3.55 & $* *$ & -3.51 & $* *$ \\
\hline & & OCC_0.25 & -3.62 & $* *$ & -0.89 & & -3.02 & $* *$ & -2.94 & $* *$ & -3.21 & $* *$ \\
\hline & & OCC_0.50 & -3.82 & $* *$ & -0.08 & & -3.10 & $* *$ & -1.81 & $\wedge$ & -3.81 & $* *$ \\
\hline & & $\mathrm{OCC}_{-}^{-} \mathrm{M}$ & -3.82 & $* *$ & -0.56 & & -3.18 & $* *$ & -2.42 & $*$ & -3.92 & $* *$ \\
\hline & CVIC_0.25 & $\mathrm{OCC}_{-}^{-} 0$ & -3.82 & $* *$ & -0.16 & & -3.26 & $* *$ & -0.32 & & -3.92 & $* *$ \\
\hline & & OCC_0.25 & -3.50 & $* *$ & -0.44 & & -3.30 & $* *$ & -0.76 & & -3.58 & $* *$ \\
\hline & & OCC_-0.50 & -0.97 & & -1.61 & & -3.54 & $* *$ & -0.94 & & -0.78 & \\
\hline & & OCC_M & -2.09 & $*$ & -0.85 & & -3.54 & $* *$ & -0.37 & & -2.20 & $*$ \\
\hline & CVIC_0.50 & OCC_0 & -3.22 & $* *$ & -0.56 & & -3.22 & $* *$ & -1.07 & & -3.36 & $* *$ \\
\hline & & OCC_0.25 & -0.40 & & -2.46 & $*$ & -2.98 & $* *$ & -1.53 & & -0.11 & \\
\hline & & OCC_0.50 & -3.46 & $* *$ & -2.74 & $* *$ & -3.82 & $* *$ & -1.59 & & -2.80 & $* *$ \\
\hline & & $\mathrm{OCC}_{-}^{-} \mathrm{M}$ & -1.33 & & -2.25 & $*$ & -3.26 & $* *$ & -1.02 & & -0.64 & \\
\hline & CVIC_M & OCC_0 & -3.14 & $* *$ & -0.32 & & -3.22 & $* *$ & -0.20 & & -3.02 & $* *$ \\
\hline & & OCC_0.25 & -1.25 & & -0.60 & & -3.42 & $* *$ & -0.72 & & -1.16 & \\
\hline & & OCC_0.50 & -1.81 & $\wedge$ & -1.89 & $\wedge$ & -3.50 & $* *$ & -1.20 & & -1.61 & \\
\hline & & OCC_M & -0.48 & & -0.60 & & -3.74 & $* *$ & -0.89 & & -0.71 & \\
\hline TCC_0.10 & CVIC_0 & OCC_O & -3.58 & $* *$ & -1.05 & & -3.26 & $* *$ & -3.62 & $* *$ & -3.55 & $* *$ \\
\hline & & OCC_0.25 & -3.66 & $* *$ & -0.93 & & -2.94 & $* *$ & -3.03 & $* *$ & -3.44 & $* *$ \\
\hline & & OCC_0.50 & -3.10 & $* *$ & -0.40 & & -2.98 & $* *$ & -2.17 & $*$ & -3.17 & $* *$ \\
\hline & & $\mathrm{OCC}_{-}^{-} \mathrm{M}$ & -3.46 & $* *$ & -0.28 & & -3.26 & $* *$ & -2.81 & $* *$ & -3.10 & $* *$ \\
\hline & CVIC_0.25 & OCC_O & -2.90 & $* *$ & -0.04 & & -3.34 & $* *$ & -1.25 & & -3.02 & $* *$ \\
\hline & & OCC_0. 0.25 & -3.02 & $* *$ & -0.64 & & -3.14 & $* *$ & -0.26 & & -2.43 & $*$ \\
\hline & & OCC_0.50 & -0.64 & & -1.61 & & -3.50 & $* *$ & -0.28 & & -0.93 & \\
\hline & & OCC_M & -1.37 & & -0.48 & & -3.50 & $* *$ & -0.02 & & -1.42 & \\
\hline & CVIC_0.50 & OCC_O & -2.78 & $* *$ & -1.01 & & -3.02 & $* *$ & -1.15 & & -2.84 & $* *$ \\
\hline & & OCC_0. 0.25 & -0.85 & & -2.42 & $*$ & -3.38 & $* *$ & -0.48 & & -1.05 & \\
\hline & & OCC_0.50 & -2.86 & $* *$ & -2.54 & $*$ & -3.22 & $* *$ & -1.68 & $\wedge$ & -2.65 & $* *$ \\
\hline & & $\mathrm{OCC}_{-}^{-} \mathrm{M}$ & -1.05 & & -2.29 & $*$ & -3.54 & $* *$ & -0.46 & & -0.64 & \\
\hline & CVIC_M & OCC_O 0 & -1.85 & $\wedge$ & -0.08 & & -3.26 & $* *$ & -0.32 & & -2.09 & $*$ \\
\hline & & OCC_0. 0.25 & -0.81 & & -0.85 & & -3.46 & $* *$ & -0.28 & & -1.05 & \\
\hline & & OCC_0.50 & -2.33 & $*$ & -2.05 & $*$ & -3.26 & $* *$ & -0.89 & & -2.20 & $*$ \\
\hline & & OCC_M & -0.77 & & -0.97 & & -3.58 & $* *$ & -0.97 & & -0.71 & \\
\hline
\end{tabular}




\begin{tabular}{|c|c|c|c|c|c|c|c|c|c|c|c|c|}
\hline \multirow[t]{3}{*}{ TCC } & \multirow[t]{3}{*}{ CVIC } & \multirow[t]{3}{*}{ OCC } & \multicolumn{2}{|c|}{$\begin{array}{c}\text { Ecological } \\
\text { outcomes }\end{array}$} & \multicolumn{6}{|c|}{ Broad vegetation } & \multicolumn{2}{|c|}{$\begin{array}{c}\text { Cost- } \\
\text { effectiveness }\end{array}$} \\
\hline & & & \multicolumn{2}{|c|}{ CVI } & \multicolumn{2}{|c|}{ Dry eucalypt } & \multicolumn{2}{|c|}{ Native grass } & \multicolumn{2}{|c|}{$\begin{array}{l}\text { Non } \\
\text { eucalypt }\end{array}$} & \multicolumn{2}{|c|}{$C V I / \$$} \\
\hline & & & $\mathrm{Z}$ & $\mathrm{P}$ & $\mathrm{Z}$ & $\mathrm{P}$ & $\mathrm{Z}$ & $\mathrm{P}$ & $\mathrm{Z}$ & $\mathrm{P}$ & $\mathrm{Z}$ & $\mathrm{P}$ \\
\hline \multirow[t]{16}{*}{ TCC_0.15 } & CVIC_0 & OCC_O & -2.42 & $*$ & -1.13 & & -2.74 & $* *$ & -3.51 & $* *$ & -2.54 & $*$ \\
\hline & & OCC_0.25 & -2.70 & $* *$ & -0.24 & & -2.78 & $* *$ & -2.62 & $* *$ & -2.35 & $*$ \\
\hline & & OCC_0.50 & -1.93 & $\wedge$ & -0.16 & & -2.66 & $* *$ & -0.52 & & -1.42 & \\
\hline & & $\mathrm{OCC}_{-} \mathrm{M}$ & -3.22 & $* *$ & 0.00 & & -3.22 & $* *$ & -2.42 & $*$ & -3.21 & $* *$ \\
\hline & CVIC_0.25 & OCC_O & -1.41 & & -0.56 & & -2.01 & $*$ & -2.01 & $*$ & -1.64 & \\
\hline & & OCC_0.25 & -1.09 & & -1.09 & & -3.38 & $* *$ & -0.50 & & -1.05 & \\
\hline & & OCC_0.50 & -0.52 & & -2.17 & $*$ & -2.82 & $* *$ & -0.76 & & -0.52 & \\
\hline & & OCC_M & -0.56 & & -1.61 & & -3.82 & $* *$ & -0.46 & & -0.34 & \\
\hline & CVIC_0.50 & OCC_O & -1.41 & & -0.93 & & -2.05 & $*$ & -0.41 & & -1.01 & \\
\hline & & OCC_0.25 & -1.29 & & -1.73 & $\wedge$ & -2.66 & $* *$ & -0.85 & & -1.23 & \\
\hline & & OCC_0.50 & -2.21 & * & -2.62 & $* *$ & -2.74 & $* *$ & -0.31 & & -1.90 & $\wedge$ \\
\hline & & $\mathrm{OCC}_{-}^{-} \mathrm{M}$ & -1.97 & $*$ & -2.50 & $*$ & -3.06 & $* *$ & -1.15 & & -1.76 & $\wedge$ \\
\hline & CVIC_M & OCC_O 0 & -0.93 & & -0.28 & & -2.58 & $*$ & -1.21 & & -0.49 & \\
\hline & & OCC_0.25 & -0.28 & & -1.69 & $\wedge$ & -3.34 & $* *$ & -0.12 & & -0.11 & \\
\hline & & OCC_0.50 & -2.82 & $* *$ & -3.62 & $* *$ & -2.74 & $* *$ & -0.41 & & -2.58 & $* *$ \\
\hline & & OCC_M & -0.77 & & -1.53 & & -3.46 & $* *$ & -0.46 & & -0.71 & \\
\hline \multirow{16}{*}{ TCC_0.20 } & CVIC_0 & OCC_0 & -1.33 & & -1.25 & & -2.78 & $* *$ & -3.14 & $* *$ & -1.49 & \\
\hline & & OCC_0.25 & -1.45 & & -1.01 & & -2.01 & $*$ & -2.70 & $* *$ & -1.57 & \\
\hline & & OCC_0.50 & -1.29 & & -0.32 & & -0.48 & & -1.61 & & -1.23 & \\
\hline & & $\mathrm{OCC}_{-}^{-} \mathrm{M}$ & -1.21 & & -0.08 & & -1.25 & & -2.09 & $*$ & -1.23 & \\
\hline & CVIC_0.25 & OCC_0 & -1.57 & & 0.00 & & -2.46 & $*$ & -0.36 & & -1.12 & \\
\hline & & OCC_0. 0.25 & -0.89 & & -1.29 & & -2.13 & $*$ & -0.41 & & -0.97 & \\
\hline & & OCC_0.50 & -1.09 & & -1.37 & & -2.54 & $*$ & -0.11 & & -0.67 & \\
\hline & & $\mathrm{OCC}_{-}^{-} \mathrm{M}$ & -0.08 & & -0.93 & & -2.82 & $* *$ & -0.63 & & -0.15 & \\
\hline & CVIC_0.50 & OCC_0 & -0.89 & & -2.09 & $*$ & -2.70 & $* *$ & -0.37 & & -0.78 & \\
\hline & & OCC_0.25 & -1.69 & $\wedge$ & -2.17 & $*$ & -2.33 & $*$ & -0.60 & & -1.31 & \\
\hline & & OCC_0.50 & -3.22 & $* *$ & -2.62 & $* *$ & -2.42 & $*$ & -0.44 & & -3.06 & $* *$ \\
\hline & & OCC_M & -2.46 & $*$ & -1.81 & $\wedge$ & -3.18 & $* *$ & -0.41 & & -2.20 & $*$ \\
\hline & CVIC_M & OCC_0 & -1.29 & & -1.53 & & -2.66 & $* *$ & -0.28 & & -0.82 & \\
\hline & & OCC_0.25 & -0.52 & & -1.53 & & -2.21 & $*$ & -0.12 & & -0.37 & \\
\hline & & OCC_0.50 & -3.14 & $* *$ & -2.70 & $* *$ & -2.33 & $*$ & -0.48 & & -2.88 & $* *$ \\
\hline & & OCC_M & -1.05 & & -2.42 & $*$ & -3.10 & $* *$ & -0.15 & & -1.08 & \\
\hline
\end{tabular}

Note: $* *, *$ and ${ }^{\wedge}$ indicate significance at $1 \%, 5 \%$ and $10 \%$ level of significance respectively

\section{Key vegetation coverage}

Mean selected bid areas for three broad vegetation types (dry eucalypt, native grassland and noneucalypt vegetation) were plotted to understand how different vegetation types are influenced by block and polygon selection (Figure 5). Together they constitute 99.5 per cent of the total area of all submitted bids under the MBHT, with the largest coverage under dry eucalypt (77\%), followed native grassland $(15 \%)$ and non-eucalypt (7\%) vegetation types.

The choice of the project selection mechanism significantly influenced vegetation coverage. Under polygon selection, the coverage of native grassland is significantly higher than block selection in all the scenarios (Figure 5). The difference is highest in the scenario where no correction (i.e., $T C C_{i}$, $O C C_{i}$ and $C V I C_{i}$ values are zero) is imposed on polygon selection. The coverage of dry eucalyptus 
vegetation is significantly higher under polygon selection than under block selection when the values of $T C C_{i}, O C C_{i}$ and $C V I C_{i}$ are higher. The coverage of non-eucalypt vegetation shows the opposite trend; that is., the coverage is significantly lower under polygon selection than under block selection when the values of $T C C_{i}, O C C_{i}$ and $C V I C_{i}$ are low (Figure 5).

This trend can be explained by considering the original bid data summaries. It has been estimated from the original bid data that the average $C V I$ score per hectare $(C V I / \mathrm{Ha} \pm \mathrm{SD})$ is highest for native grassland $(13.28 \pm 4.75)$, followed by dry eucalypt $(10.79 \pm 4.84)$ and non-eucalypt $(8.28 \pm$ 3.63). However, bids per hectare $(\$ / \mathrm{Ha})$ is highest for non-eucalypt $(\$ 1,362 / \mathrm{Ha} \pm \$ 1,387 / \mathrm{Ha})$ followed by native grassland $(\$ 1,048 / \mathrm{Ha} \pm \$ 749 / \mathrm{Ha})$ and dry eucalypt $(\$ 1,018 / \mathrm{Ha} \pm \$ 917 / \mathrm{Ha})$. Therefore, when $T C C_{i}, O C C_{i}$ and $C V I C_{i}$ values are small, polygon selection selects grassland vegetation types as much as possible, since it is most cost-effective. However, with a gradual increase in $T C C_{i}$, OCC $_{i}$ and $C V I C_{i}$ values, it becomes more expensive to select isolated native grassland vegetation patches. The optimisation accounts for this by selecting dry eucalypt vegetation patches when possible, which are relatively larger in area but contain lower CVI scores than native grasslands, but higher $C V I$ scores than non-eucalyptus vegetation types. 

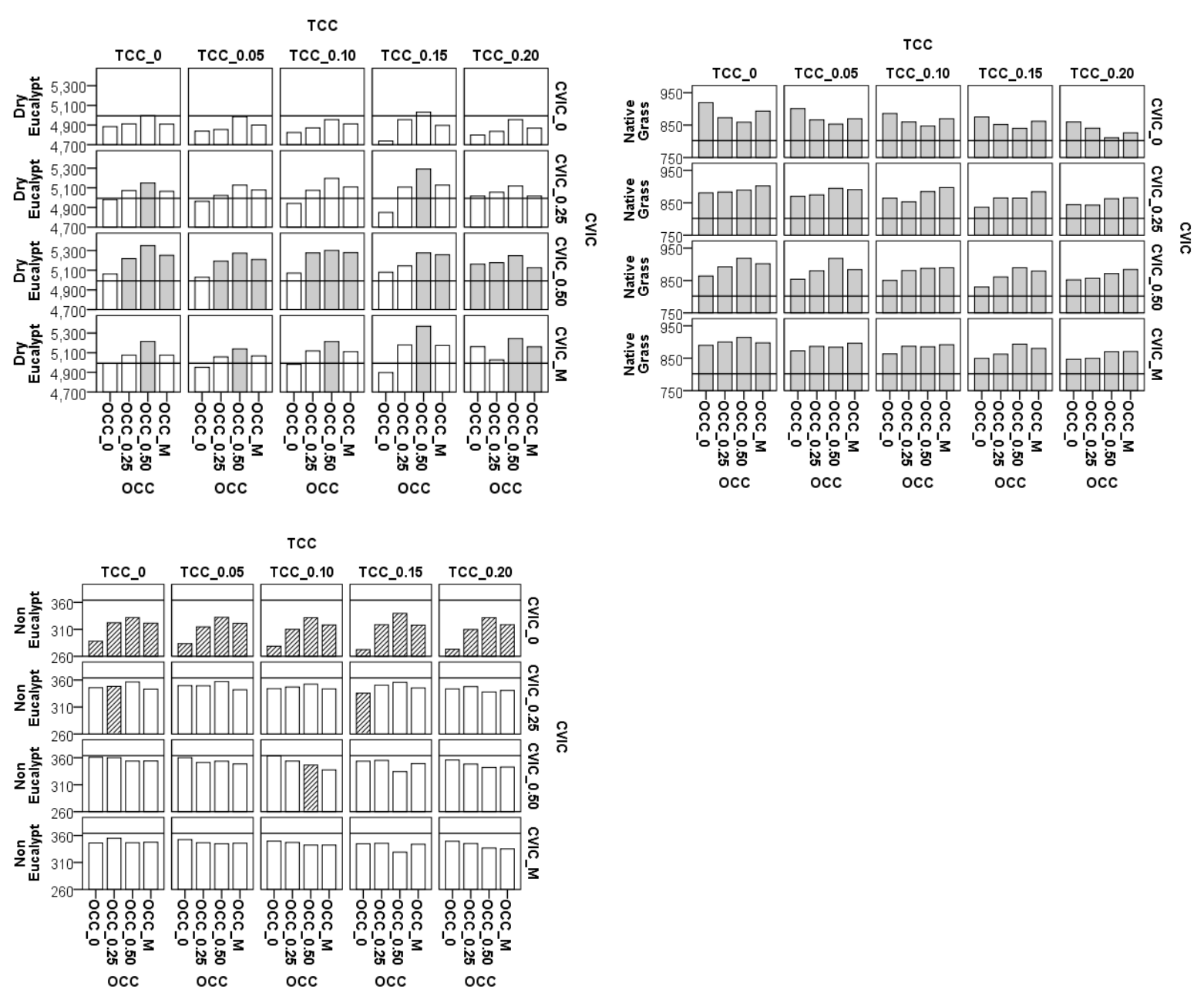

Figure 5: Average coverage (Ha) of broad vegetation types under block selection and polygon selections with different $T C C_{i}, O C C_{i}$ and $C V I C_{i}$ values.

Each point represents average of optimization results for twenty levels of budget constraints. Reference line indicates estimate for block selection. Shaded, checked and blank bars indicate significantly better performance by polygon selection, by block selection and no significant difference respectively at $10 \%$ level of significance based on Wilcoxon Signed Ranks Test (Table 2).

\section{Cost-effectiveness}

Agencies are often primarily interested in the cost-effectiveness of different approaches to achieving policy outcomes. Figure 6 shows the plotted $C V I / \$$ achieved under different budget constraints in the scenario with no correction factors (i.e., $T C C_{i}, O C C_{i}$ and $C V I C_{i}$ values are zero) applied to polygon selection. Similar to total CVI score estimates, the difference between polygon and block selection is larger when the budget is small. For example, with $\$ 0.50, \$ 1$ and $\$ 1.5$ million budget constraints, polygon selection has achieved 22, 26 and 15 per cent higher CVI scores per dollar respectively. The 
difference between the selection mechanisms is gradually reduced as the budget increases. This is not surprising; since with additional budget, more expensive projects (with relatively lower CVI score) are included in the portfolio. It is also possible that as the budget increases, optimal polygon selection does not need to divide the projects and both mechanisms act similarly. Overall, across the budget constraint range, compared to block selection, the average CVI score per dollar is ten per cent higher under polygon selection with zero $T C C_{i}, O C C_{i}$ and $C V I C_{i}$ values.

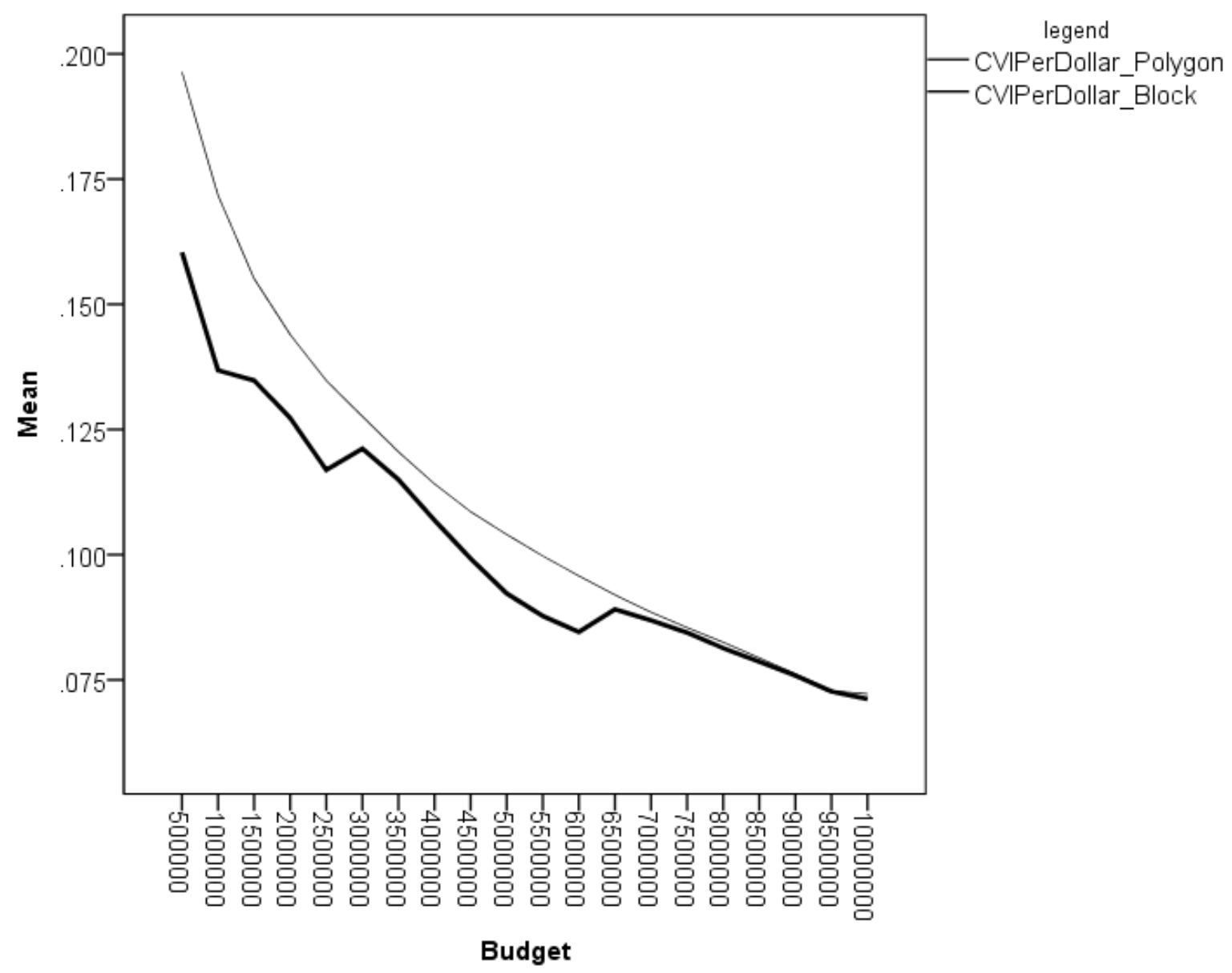

Figure 6: Average conservation value index $(C V I)$ score per dollar $(C V I / \$)$ for block selection and polygon selections for different budget constraint for the scenario with no correction factor (i.e., $T C C_{i}$, OCC $_{i}$ and $C V I C_{i}$ values set to zero).

Average CVI scores per dollar (CVI/\$) under individual correction factors combinations are plotted in Figure 7. Polygon selection performs better than block selection for scenarios with low $T C C_{i}, O C C_{i}$ and $C V I C_{i}$ values. For example, with TCC_0, TCC_0.05 and TCC_0.10 scenarios, the average CVI scores per dollar for polygon selection are significantly higher for zero and medium (0.25) levels of 
$O C C_{i}$ and $C V I C_{i}$ values. With higher $T C C_{i}, O C C_{i}$ and $C V I C_{i}$ values, average scores are equal to or less than similar block selections ${ }^{6}$.

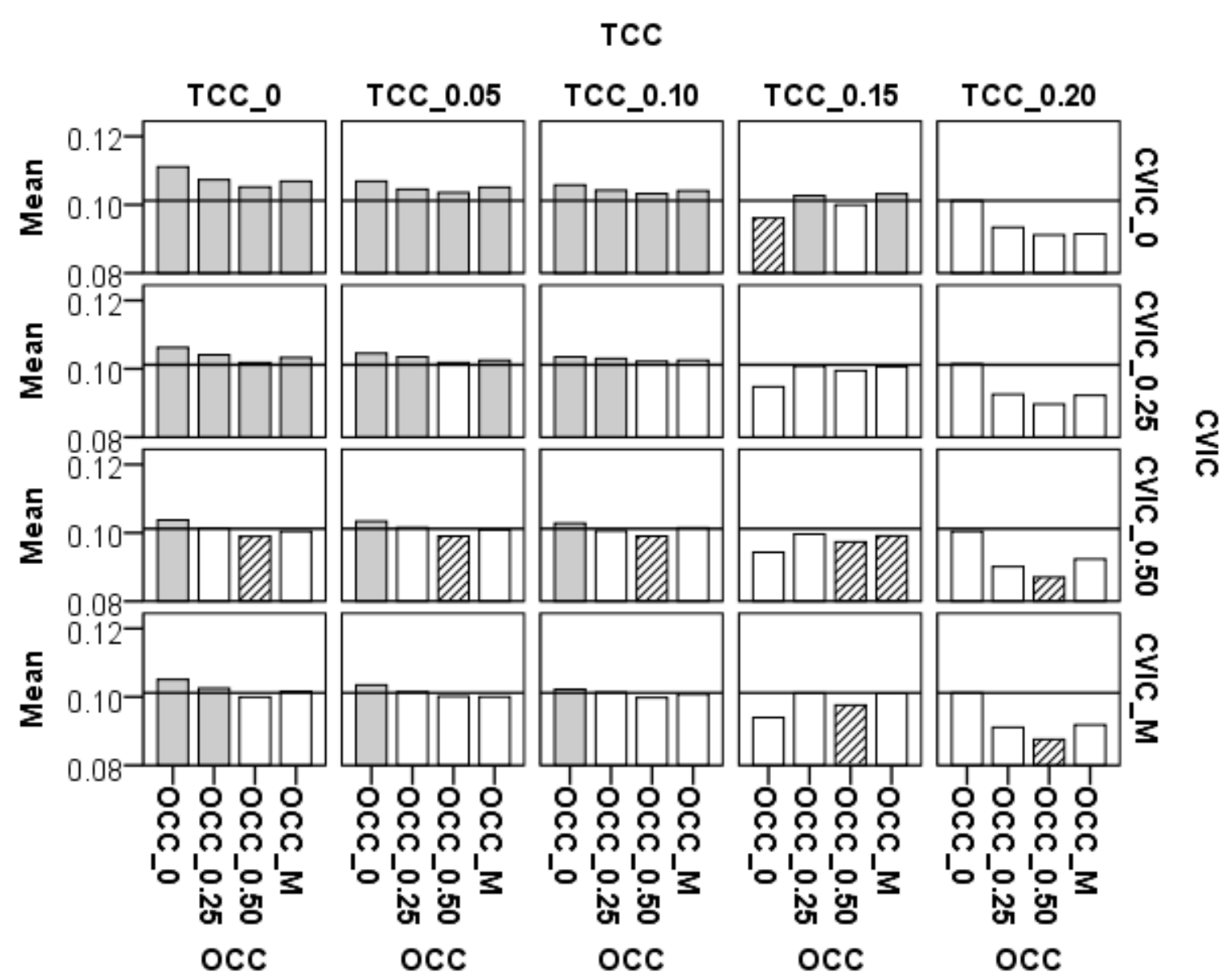

Figure 7: Average conservation value index $(C V I)$ score per dollar $(C V I / \$)$ for block selection and polygon selections with different $T C C_{i}, O C C_{i}$ and $C V I C_{i}$ values.

Each point represents average of optimization results for twenty levels of budget constraints. Reference line indicates estimate for block selection. Shaded, checked and blank bars indicate significantly better performance by polygon selection, by block selection and no significant difference respectively at 10 per cent level of significance based on Wilcoxon Signed Ranks Test (Table 2).

In summary, the results indicate that 'discreteness' or 'lumpiness' in the current project selection could negatively influence cost effectiveness of conservation tenders. Based on the MBHT conservation auction data, the study found that with a small budget, the cost-effectiveness loss could be

\footnotetext{
${ }^{6}$ Analytically, performance under a polygon selection should be at least equal to block selection as a globally optimal solution in a polygon selection problem should include optimal solution under block selection. However, due to non-linear integer nature of the problem, under polygon selection it is not always possible to find a global optimal solution. Therefore, in some cases, polygon selection underperformed.
} 
as high as one-quarter under the commonly practiced 'all or nothing' project selection approach. In essence, an application of partial project selection with non-linear corrections on bid prices and ecological scores has the potential to improve cost-effectiveness of conservation programs. Improved performances result from better targeting of vegetation patches with higher ecological values (such as native grassland). However, as expected, the performance of the polygon selection gradually declines as higher correction factors are imposed.

\section{Discussion}

The problem with 'lumpy' (or all-or-nothing) project selection has been identified in the literature as a major problem in conservation policy (Connor et al. 2008; Chan et al. 2003); however, the extent of the problem has been rarely quantified. Using data from the MBHT program, it was shown that conservation tenders could suffer from a loss in cost-effectiveness from binary 'all or nothing' project selections. The loss in cost-effectiveness could be as high as one-quarter of that possible. The study demonstrated the importance for agencies to be cognizant of program design. The work strongly suggests that agencies should consider alternative project selection approaches with better targeting capabilities.

There is scope to further the analysis. For example, the non-linear corrections applied to the bid prices and ecological value scores do not have to be uniform. Bid price correction factors could be different for different industry / landholder types. Similarly, the conservation value index score correction could be different for different ecosystem or vegetation types. It is also possible to extend the work by considering scoring matrices specifically designed for any particular landscape and set of conservation objectives. These could, for instance, provide a more tailored scoring matrix that corrects for loss of contiguity. Moreover, it is highly likely that bidding behaviour could be significantly different under different project selection mechanisms. Therefore, this approach should be further tested using laboratory experiments and agent based simulations before field trials.

\section{Conclusion}

Conservation auctions are an important environmental policy tool. There is potential to improve cost effectiveness by using a well-designed auction program. This article contributes to environmental policy development by exploring whether partial project selection can improve cost-effectiveness of conservation auctions. The simulation analysis, based on real world auction data, shows that in some scenarios it is possible to improve cost effectiveness by using partial selection and contracting. 
The sensitivity analysis indicates that the financial efficiency of conservation incentive payment programs could be increased by using a partial project selection process, especially when compensation for the loss of economies of scope and scale in conservation costs and the loss of ecological benefits are low. In practical terms, this approach may allow environmental planning agencies to sharpen the selection of polygons to suit their policy objectives, while allowing a sliding scale of compensation to landholders for loss of scope and scale. This may be of benefit where the high conservation value assets (as defined by polygons) do not rely on connectivity to the surrounding 'matrix' or when high value polygons are geographically dispersed. This benefit may be enhanced where the environmental planning agency's budget is limited compared to the bids offered.

\section{References}

Armsworth, PR, Acs, S, Dallimer, M, Gaston, KJ, Hanley, N \& Wilson, P 2012, 'The cost of policy simplification in conservation incentive programs', Ecology Letters, vol. 15, pp. 406 - 414.

Bamière, L, David, M \& Vermont, B 2013, 'Agri-environmental policies for biodiversity when the spatial pattern of the reserve matters', Ecological Economics, vol. 85, pp. 97-104.

Boxall, PC, Perger, O \& Weber, M 2013, 'Reverse Auctions for Agri-Environmental Improvements: Bid-Selection Rules and Pricing for Beneficial Management Practice Adoption', Canadian Public Policy, vol. 39 (Supplement 2), pp. S23-S36.

Chan, C, Laplagne, P \& Appels, D 2003, 'The role of auctions in allocating public resources', Melbourne, Australia: Productivity Commission.

Connor, JD, Ward, JR \& Bryan, B 2008, 'Exploring the cost effectiveness of land conservation auctions and payment policies', Australian Journal of Agricultural and Resource Economics, vol. 52, pp. 303-319.

Ducos, G, Dupraz, P \& Bonnieux, F 2009, 'Agri-environment contract adoption under fixed and variable compliance costs', Journal of Environmental Planning and Management, vol. 52, no. 5, pp. 669-687.

Falconer, K 2000, 'Farm-level constraints on agri-environmental scheme participation: a transactional perspective', Journal of Rural Studies, vol. 16, pp. 379-394.

Hailu, A. \& Thoyer, S. 2007. 'Designing multi-unit multiple bid auctions: An agent-based computational model of uniform, discriminatory and generalised Vickrey auctions', Economic Record, vol. 83, no. S1, pp. S57-S72.

Hajkowicz, S, Collins, K \& Cattaneo, A 2009, 'Review of Agri-Environment Indexes and Stewardship Payments', Environmental Management, vol. 43, pp. 221-236.

Iftekhar, M, Hailu, A \& Lindner, R 2014. 'Does it pay to increase competition in combinatorial conservation auctions?', Canadian Journal of Agricultural Economics/Revue canadienne d'agroeconomie, vol. 62, pp. 411-433. 
Iftekhar, MS, Hailu, A \& Lindner, RK 2012a. 'Combinatorial auction designs for biodiversity conservation', Society \& Natural Resources: An International Journal, vol. 25, pp. 965-979.

Iftekhar, MS, Hailu, A \& Lindner, RK 2012b. 'Combinatorial auctions for procuring agri-environmental services: A review of some design issues', Australasian Journal of Environmental Management, vol. 19, pp. 79 - 90.

Iftekhar, MS, Tisdell, JG \& Sprod, D 2013, A review of conservation project selection criteria in the Midlands Biodiversity Hotspot Tender, Tasmania: Sensitivity to project duration and auction budget. LaP Hub Report, http://www.nerplandscapes.edu.au/publication/review-conservationproject-selection-criteria-midlands-biodiversity-hotspot-tender (last accessed 25/02/2016).

Latacz-Lohmann, U \& Hamsvoort, CVD 1997, 'Auctioning conservation contracts: A theoretical analysis and an application', American Journal of Agricultural Economics, vol. 79, pp. 407-418.

Latacz-Lohmann, U \& Hamsvoort, CVD 1998, 'Auctions as a means of creating a market for public goods from agriculture', Journal of Agricultural Economics, vol. 49, pp. 334-345.

Latacz-Lohmann, U \& Schilizzi, S 2005, Auctions for conservation contracts: A review of the theoretical \& empirical literature. Edinburgh: Scottish Executive Environment and Rural Affairs Department.

Mettepenningen, E, Verspecht, A \& Van Huylenbroeck, G 2009, 'Measuring private transaction costs of European agri-environmental schemes', Journal of Environmental Planning and Management, vol. 52, pp. 649-667.

Nilsson, FOL 2009, 'Transaction costs and agri-environmental policy measures: are preferences influencing policy implementation?', Journal of Environmental Planning and Management, vol. 52, pp. 757-775.

Reimer, AP \& Prokopy LS 2014, 'Farmer participation in U.S. Farm Bill conservation", Environmental Management, vol. 53, pp. 318-332.

Ruto, E \& Garrod, G 2009, 'Investigating farmers' preferences for the design of agri-environment schemes: a choice experiment approach', Journal of Environmental Planning and Management, vol. 52, pp. 631-647.

Schroeder, LA, Isselstein, J, Chaplin, S \& Peel, S 2013, 'Agri-environment schemes: Farmers' acceptance and perception of potential 'Payment by Results' in grassland-A case study in England', Land Use Policy, vol. 32, pp. 134-144.

Stoneham, G, Chaudhri, V, Ha, A \& Strappazzon, L 2003, 'Auctions for conservation contracts: an empirical examination of Victoria's BushTender trial', The Australian Journal of Agricultural and Resource Economics, vol. 47, pp. 477-500.

USDA 2012, Conservation Reserve Program: Monthly Summary October 2012, Washington, DC U.S. Department of Agriculture. 
